\title{
A prospective study of depression and mortality in patients with type 2 diabetes: the Fremantle Diabetes Study
}

Received: 27 May 2005 / Accepted: 22 July 2005 / Published online: 15 November 2005

(C) Springer-Verlag 2005

\begin{abstract}
Aims/hypothesis: Depression is associated with excess mortality in patients with type 2 diabetes. We investigated the impact, and possible causal mechanisms, of depression on all-cause and cardiac mortality in patients with type 2 diabetes. Methods: We recruited 1,273 patients with type 2 diabetes from a postcode-defined community (average age $64.1 \pm 11.2$ years, $48.7 \%$ males, median duration of diabetes 4 years [range 1.0-9.0]) and followed them for $7.8 \pm 2.4$ years. Depression was assessed using data obtained using a quality-of-life questionnaire, and cause and date of death were obtained from the state registry. Results: Depression was present in $31.5 \%$ of subjects at recruitment. Depressed subjects had a longer duration of diabetes, more cardiovascular risk factors, CHD, cerebrovascular disease and diabetic microvascular complications at baseline, and higher all-cause and cardiac mortality rates during follow-up. In Cox proportional hazards models and after adjustment for demographic and diabetes-related variables and cardiovascular risk factors, depression was significantly associated with excess all-cause and cardiac mortality. When diabetic microvascular and macrovascular complications were added to the Cox models, depression was not significantly associated with excess all-cause or cardiac mortality. Conclusions/interpretation: Depression in patients with type 2 diabetes is associated with a greater prevalence of complications but is not an independent predictor of all-cause or cardiac mortality. Depression may contribute to the progression of important prognostic var-
\end{abstract}

D. G. Bruce $(\bowtie) \cdot$ W. A. Davis · T. M. E. Davis

School of Medicine and Pharmacology,

University of Western Australia,

Perth, WA, Australia

e-mail: dbruce@cyllene.uwa.edu.au

Tel.: +61-8-94313229

Fax: $+61-8-94313227$

S. E. Starkstein

School of Psychiatry and Neuroscience,

University of Western Australia,

Perth, WA, Australia iables in diabetes, particularly macrovascular and microvascular disease.

Keywords Cardiac mortality · Depression ·

Diabetic complications - Mortality - Prospective study ·

Type 2 diabetes

Abbreviations ABI: ankle:brachial index - ACR: albumin:creatinine ratio - CVD: cerebrovascular disease DSM-IV: Diagnostic and Statistical Manual of Mental Disorders, 4th edition - FDS: Fremantle Diabetes Study . GHS: General Health Status Questionnaire - PAD: peripheral arterial disease

\section{Introduction}

The prevalence both of clinical depression and of depressive symptoms in diabetic subjects is twice that in the general population [1], and older diabetic adults may be especially susceptible to depression $[2,3]$. Depression in diabetes has been considered to result from the burden of disease, but there is emerging evidence that depression can also precede the development of type 2 diabetes $[4,5]$. The combination of diabetes and depression confers a poor prognosis on affected individuals [6]. In cross-sectional studies, patients with diabetes and depression have high rates of diabetic complications [7] and poor glycaemic control [8]. In the only longitudinal study of depression in type 2 diabetes, depressed patients developed more microvascular and macrovascular disease, greater degrees of physical disability and had a higher all-cause mortality rate than unaffected diabetic subjects [9]. The presence of depressive symptoms, even if below cut-off scores on a rating scale for major depression, was also associated with adverse outcomes [9].

The most common major complication [10] and cause of death [11] in patients with type 2 diabetes is CHD. Recent reviews have concluded that depression increases the risk of CHD in the general population [12] and significantly worsens prognosis [13]. There are no equivalent data 
examining the effect of depression on cardiac mortality in patients with diabetes. We have analysed data from a large, well-characterised community-based cohort of patients with type 2 diabetes to assess the impact of depression on subsequent all-cause and cardiac mortality. Given that any effect of depression on survival is likely to be mediated by diabetic complications, or important diabetes-related prognostic factors, including glycaemia and cardiovascular risk factors, we assessed the role of a wide range of demographic and clinical factors known to directly or indirectly influence these variables in type 2 diabetes.

\section{Subjects and methods}

\section{Subjects}

The Fremantle Diabetes Study (FDS) was a prospective observational study of diabetic patients from a postcodedefined community of 120,097 people in Fremantle, Western Australia. The FDS protocol was approved by the Human Rights Committee, Fremantle Hospital, and all subjects gave informed consent before participation. We identified 2,258 subjects with diabetes between 1993 and 1996 using a variety of methods (surveillance of hospital inpatient and outpatient clinic lists, notification through local general practitioners and allied health services such as diabetes education, podiatry and dietetics, and advertisements in local pharmacies and local media). From these subjects we recruited $1,426(63 \%)$ to annual assessments, of whom $1,294(91 \%)$ had type 2 diabetes. The present study included 1,273 type 2 diabetic subjects who satisfactorily completed questionnaire assessments of depression at study entry. Type 2 diabetes was defined clinically, after excluding secondary diabetes, as that (1) treated with diet and/or oral hypoglycaemic agents irrespective of age at diagnosis; (2) in patients aged $\geq 60$ years at diagnosis whatever the treatment history; and (3) diagnosed between 40 and 60 years of age, treated with insulin at study entry but not at diagnosis, and associated with a BMI $>30 \mathrm{~kg} / \mathrm{m}^{2}$. Identification and recruitment methods, sample characteristics (including classification of diabetes) and details of non-recruited patients have been described in more detail elsewhere [14-16].

\section{Clinical and laboratory methods}

Baseline assessment We recorded detailed patient data that included diabetes-specific variables, co-morbid conditions and their treatment, smoking and alcohol use, social, economic and educational status, self-assessment of ethnic background, fluency in English and recent physical exercise [14, 17]. All FDS subjects underwent a full clinical examination and provided fasting blood and urine samples for standard biochemical tests including serum glucose, $\mathrm{HbA}_{1} \mathrm{c}$, serum lipoproteins and albumin:creatinine ratio (ACR) $[14,16]$. Peripheral sensory neuropathy was defined using the clinical portion of the Michigan
Neuropathy Screening Instrument [18]. A subject was defined as having 'any retinopathy' if any grade of retinopathy, including maculopathy, was detected by direct and/or indirect ophthalmoscopy in one or both eyes and/ or more detailed data in patients assessed for photocoagulation. Self-reported stroke and transient ischaemic attack were amalgamated with prior hospitalisations for these conditions to define baseline cerebrovascular disease (CVD) status. Patients were classified as having CHD if there was a self-reported/hospital history of myocardial infarction, angina, coronary artery bypass grafting, angioplasty, and/or definite myocardial infarction on Minnesota coding of a resting 12-lead ECG (codes 1-1, 1-2) [16]. The ankle:brachial index (ABI) was obtained from brachial and ankle systolic blood pressures using Doppler detection and peripheral arterial disease (PAD) was defined as an $\mathrm{ABI} \leq 0.90$ or the presence of a diabetes-related lowerextremity amputation.

Depression symptoms Subjects self-rated the General Health Status questionnaire (GHS) [19]. The GHS was selected from the quality-of-life scales that were available at the time the FDS was designed (1991) to provide valid information relating to several health dimensions in a time-efficient manner. A full explanation of the aim and nature of the questionnaire was provided and an interpreter was used when patients did not speak English fluently.

The GHS covers general mobility (selection of one of six states), self-care (rating of difficulty with washing, dressing, eating and using the toilet), usual activity (selection of one of four states), social and personal relationships (whether health status impacts on social life, contact with relatives/friends, leisure and sex life), feelings (rating of 25 states on visual analogue scales) and general health (single visual analogue rating). The GHS includes questions on mood and subjects are presented with a list that includes the following depressive symptoms (feeling sad or depressed, anxious or worried, uncertainty about the future, anger or resentment, guilt, loneliness, loss of selfconfidence, difficulty sleeping, lack of energy, inability to concentrate) and are asked: 'Over the last 2 weeks, has your state of health led you to experience any of these feelings? If so, how much distress have they caused you?' Each symptom is presented on a $10-\mathrm{cm}$ visual analogue scale that is anchored by 'No distress at all' on the left and 'Extreme distress' on the right.

Validation of depression assessment Since the GHS has not been used previously to assess depression, we examined its validity in a convenience sample of 51 subjects with type 2 diabetes (mean age $67.7 \pm 6.0$ years; 60.8\% males) drawn from other research studies. A trained researcher rated these subjects for the presence of depression syndromes using a validated, semi-structured diagnostic interview for making the major Axis I, Diagnostic and Statistical Manual of Mental Disorders, 4th edition (DSM-IV) depression diagnoses (MINI Screen, version 5.0). All the information and subsequent diagnoses 
were reviewed by a psychiatrist with experience of depression in clinical disorders (S. E. Starkstein). We decided a priori that GHS depression symptoms were present if the subjects rated themselves at $5 \mathrm{~cm}$ (i.e. $50 \%$ ) or more on the visual analogue scale. In addition, subjects were not required to report sadness, which is required for the DSM-IV diagnosis of major depression, because depressed older persons often do not exhibit the symptom sadness [20] and there is a high frequency of subsyndromal depression in old age [21].

The association between one or more, two or more and three or more GHS symptoms of depression, respectively, and DSM-IV depression was assessed. We also assessed the effect of making the presence of sadness mandatory for a diagnosis of depression. Twelve of the 51 patients $(24 \%)$ had clinical depression based on DSM-IV criteria (six major depression, three minor depression and three dysthymia). The presence of two or more GHS symptoms proved a strong predictor of clinical depression because ten of the 12 depressed patients reported two or more GHS symptoms compared with only two of the 39 non-depressed subjects $\left(\chi^{2}=31.19, p<0.0001\right)$ with $83.3 \%(95 \%$ CI: $50.9-97.1 \%$ ) sensitivity, $94.9 \%$ (CI: 81.4-99.1\%) specificity, $83.3 \%$ (CI: $50.9-97.1 \%$ ) positive predictive value and $94.9 \%$ (CI: 81.4-99.1\%) negative predictive value in this sample. Using the presence of one or more GHS symptom reduced the positive predictive value to $<70 \%$ and using three or more symptoms or mandating that sadness be present reduced the sensitivity to $50 \%$ or less. The presence of two or more GHS symptoms was therefore taken as indicating depression in the FDS patients.

Mortality data A government register records the details of all deaths in Western Australia and is part of the larger Western Australian Data Linkage System [22]. These sources provided all-cause and cardiac mortality from the beginning of the study until the end of June 2003. The causes of death were reviewed independently by two of the authors (D. G. Bruce and T. M. E. Davis) and classified as having cardiac causes or not under the same system as used in the UK Prospective Diabetes Study [23]. When there was disagreement between the raters, a final decision was based on consensus.

Data analysis and statistical methods

The computer package SPSS for Windows (Version 11.5; SPSS Inc., Chicago, IL, USA) was used for statistical analysis. Data are presented as proportions, means (standard deviation, $\mathrm{SD}$ ), geometric mean (SD range), or, in the case of variables which did not conform to a normal or lnnormal distribution, median (interquartile range). Student's $t$ test was used for comparison of two means, Fisher's exact test was used for two proportions, and the $\chi^{2}$ test was used for multiple proportions. Two-group non-parametric comparisons were by Mann-Whitney $U$ test. A significance level of $p<0.05$ was used throughout.
Cumulative survival curves constructed using KaplanMeier estimates for patients remaining alive in the two groups defined by baseline depression status were compared using log-rank tests. Cox proportional hazards modelling (forward conditional, variable entry and removal with $p<0.05$ and $p>0.10$, respectively) was used to determine independent predictors of all-cause and cardiac mortality. All clinically plausible univariate variables with $p<0.20$ were considered for entry into the models. We explored the role of depression and diabetic complications in death by constructing two Cox models for each of allcause and cardiac mortality: (1) baseline demographic, diabetes-related and cardiovascular risk factors alone (Model A); and (2) Model A plus individual macrovascular and microvascular diabetic complications (Model B).

\section{Results}

Baseline data and crude mortality

Amongst the 1,273 patients, 53.7\% reported no depressive symptoms and $14.8 \%$ reported a single depressive symptom. The $31.5 \%$ who reported at least two symptoms were classified as having depression. Table 1 summarises the baseline characteristics of subjects classified by depression status. Depressed subjects were more likely to be female, to have diabetes of longer duration, to consume less alcohol, to take less physical exercise, and to be more obese, to have worse serum lipid profiles and a greater prevalence of CVD, CHD and microalbuminuria. They were also more likely to be taking antidepressant medication, although only $12 \%$ were doing so. After a mean follow-up of $7.8 \pm$ 2.4 years, $369(28.5 \%)$ had died, $152(11.9 \%)$ from cardiac causes. Depressed subjects were significantly more likely to have died of all causes as well as of cardiac causes.

\section{Predictors of all-cause mortality}

A large number of variables including depression were significantly associated in univariate analyses with allcause mortality. Cumulative survival curves, constructed using Kaplan-Meier estimates, of patients remaining alive by depression status were significantly different (Fig. 1, $p=0.0023, \log$-rank test). Cox proportional hazards modelling was used to explore independent predictors of time to death from all causes (Table 2). In the models, there were significant interactions between $\ln ($ time $)$ and depression status $(p<0.025)$, indicating that the proportional hazards assumptions may be invalid. However, the $\log (-\log$ [survival]) curves were parallel and inspection of the residual beta versus time plots for all significant covariates revealed no outliers. It was therefore concluded that the non-proportionality made no difference to the interpretation of the data [24].

After adjustment for demographic, diabetes-related and cardiovascular risk factors, but not for diabetic complications (Table 2, Model A), baseline depression status was 
Table 1 Baseline characteristics and follow-up crude mortality rates of 1,273 patients with type 2 diabetes classified by the presence or absence of depression

\begin{tabular}{|c|c|c|c|}
\hline & Non-depressed group & Depressed group & $p$ value \\
\hline$n$ & 872 & 401 & \\
\hline Age (years) & $64.5 \pm 10.7$ & $63.2 \pm 12.2$ & 0.07 \\
\hline Male (\%) & 51.4 & 42.9 & 0.005 \\
\hline Marital status (\% married) & 67.2 & 62.6 & 0.11 \\
\hline Educational level ( $\% \geq$ primary $)$ & 74.7 & 72.5 & 0.41 \\
\hline English fluency (\% low fluency) & 15.3 & 14.0 & 0.61 \\
\hline \multicolumn{4}{|l|}{ Ethnic background (\%) } \\
\hline Anglo-Celt & 65.1 & 61.1 & 0.17 \\
\hline South European & 18.7 & 16.2 & 0.31 \\
\hline Other European & 8.3 & 9.2 & 0.59 \\
\hline Asian & 2.5 & 4.5 & 0.08 \\
\hline Mixed/other & 4.2 & 7.2 & 0.029 \\
\hline Indigenous Australian & 1.1 & 1.7 & 0.43 \\
\hline Diabetes duration (years) & $3.5(0.9-8.0)$ & $4.6(1.0-10.0)$ & 0.014 \\
\hline BMI $\left(\mathrm{kg} / \mathrm{m}^{2}\right)$ & $29.4 \pm 5.3$ & $30.0 \pm 5.7$ & 0.07 \\
\hline Waist circumference ( $\%$ obese $)$ & 62.2 & 69.0 & 0.019 \\
\hline Systolic BP (mmHg) & $151 \pm 24$ & $151 \pm 24$ & 0.72 \\
\hline Diastolic BP (mmHg) & $81 \pm 11$ & $80 \pm 11$ & 0.62 \\
\hline Antihypertensive medication (\%) & 50.2 & 53.1 & 0.37 \\
\hline Fasting plasma glucose $(\mathrm{mmol} / \mathrm{l})$ & $8.5(6.9-10.7)$ & $8.2(6.7-10.7)$ & 0.35 \\
\hline $\mathrm{HbA}_{1} \mathrm{c}(\%)$ & $7.4(6.4-8.8)$ & $7.5(6.4-8.8)$ & 0.89 \\
\hline \multicolumn{4}{|l|}{ Diabetic therapy $(\%)$} \\
\hline Diet & 32.0 & 32.4 & 0.90 \\
\hline Oral agents & 56.4 & 55.3 & 0.72 \\
\hline Insulin & 9.2 & 9.8 & 0.76 \\
\hline Insulin plus oral agents & 2.4 & 2.5 & 1.00 \\
\hline Total cholesterol (mmol/l) & $5.4 \pm 1.1$ & $5.6 \pm 1.2$ & 0.024 \\
\hline HDL-cholesterol (mmol/1) & $1.07 \pm 0.32$ & $1.04 \pm 0.32$ & 0.23 \\
\hline Triglycerides (mmol/l) & $1.8(1.1-3.2)$ & $2.0(1.2-3.6)$ & 0.003 \\
\hline Lipid-lowering medication (\%) & 10.2 & 11.3 & 0.62 \\
\hline CVD (\%) & 8.3 & 13.3 & 0.008 \\
\hline CHD (\%) & 29.7 & 36.0 & 0.027 \\
\hline PAD (\%) & 28.8 & 34.1 & 0.064 \\
\hline Retinopathy (\%) & 15.7 & 16.7 & 0.68 \\
\hline Neuropathy (\%) & 29.8 & 33.9 & 0.16 \\
\hline $\mathrm{Ln}(\mathrm{ACR})(\mathrm{mg} / \mathrm{mmol})$ & $2.9(0.7-11.8)$ & $3.6(0.7-17.4)$ & 0.023 \\
\hline \multicolumn{4}{|l|}{ Smoking status (\%) } \\
\hline Never & 45.8 & 42.1 & 0.22 \\
\hline Ex-smoker & 40.3 & 40.1 & 0.95 \\
\hline Current & 13.8 & 17.9 & 0.06 \\
\hline Exercise in past 2 weeks (\%) & 76.0 & 63.5 & $<0.001$ \\
\hline Standard alcoholic drinks/day & $0(0-0.8)$ & $0(0-0.3)$ & 0.006 \\
\hline Antidepressant medication (\%) & 4.1 & 12.2 & $<0.001$ \\
\hline \multicolumn{4}{|l|}{ Deceased by 30 June 2003 (\%) } \\
\hline All cause & 25.7 & 34.2 & 0.002 \\
\hline Cardiac & 10.6 & 15.0 & 0.026 \\
\hline
\end{tabular}

independently associated with time to death with an excess mortality of $38 \%$. When diabetic complications were added (Table 2, Model B), depression status was associated with a non-significant $21 \%$ increase in all-cause mortality. We examined for interactions between each of the main effects and depression in this model and found no significant interactions. In a Cox model that included for comparison purposes only adjustments for age, sex, diabetes duration and indigenous ethnicity, depression status was independently associated with time to death with a significant 


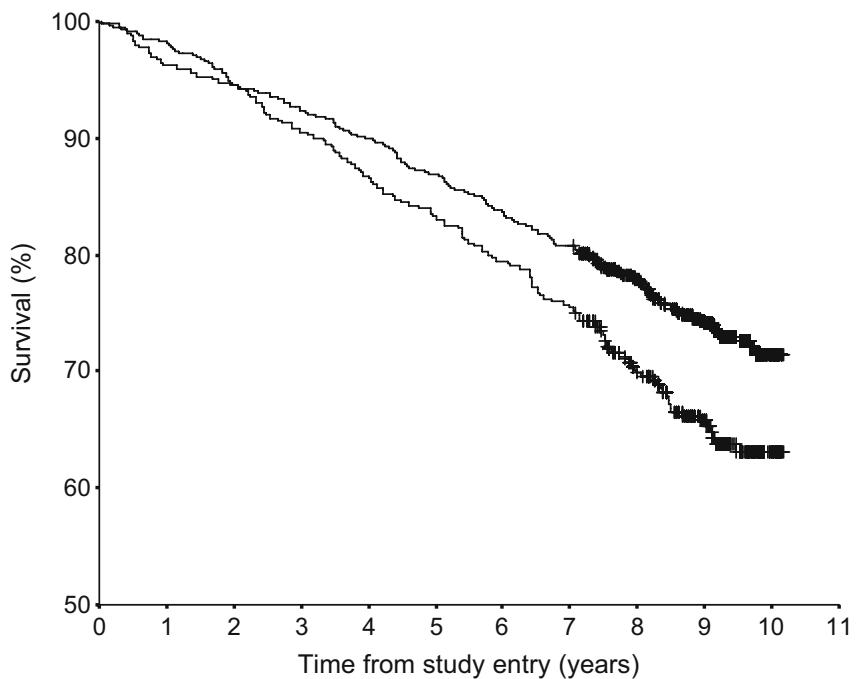

Fig. 1 Survival probability curves derived from Kaplan-Meier analysis of percentages of patients remaining alive in two groups of patients defined by baseline depression status. The upper line denotes patients who were free of depression at baseline. The crosses indicate censored data points excess all-cause mortality of $49.3 \%$ (95\% CI $20.4-85.1 \%$, $p<0.001)$.

Predictors of cardiac mortality

CHD was the commonest cause of death (41.2\%). As with all-cause mortality, a large number of baseline variables including depression were significantly associated with cardiac death in univariate analyses. Cumulative survival curves for patients defined by baseline depression and cardiac death were significantly different (Fig. 2, $p<$ $0.0169, \log$-rank test). Cox models of predictors of cardiac death were constructed as described above. After adjustment for demographic, diabetes-related and cardiovascular risk factors, but excluding diabetic complications, depression status was associated with a significant $56 \%$ increase in cardiac mortality (Table 3, Model A). After adjustment for all relevant variables, including complications, depression status was associated with a non-significant $15 \%$ increase in cardiac mortality (Table 3, Model B). We found no significant interactions between each of the main effects and depression in this model. In a Cox model adjusting

Table 2 Cox proportional hazards models of baseline predictors of time to death from all causes in patients with type 2 diabetes

\begin{tabular}{|c|c|c|c|c|c|}
\hline & & $\begin{array}{l}\text { Model A hazard ratio } \\
(95 \% \mathrm{CI})\end{array}$ & $p$ value & $\begin{array}{l}\text { Model B hazard ratio } \\
(95 \% \mathrm{CI})\end{array}$ & $p$ value \\
\hline Age (increase of 1 year) & & $1.10(1.07-1.10)$ & $<0.001$ & $1.08(1.07-1.10)$ & $<0.001$ \\
\hline \multirow[t]{2}{*}{ Gender } & Female & 1 & & 1 & \\
\hline & Male & $1.73(1.38-2.16)$ & $<0.001$ & $1.77(1.39-2.26)$ & $<0.001$ \\
\hline Duration DM (increase of 1 year) & & $1.02(1.01-1.04)$ & 0.003 & - & - \\
\hline $\mathrm{HbA}_{1} \mathrm{c}$ (increase of $1 \%$ ) & & $1.09(1.02-1.16)$ & 0.016 & - & - \\
\hline \multirow[t]{2}{*}{ BP-lowering therapy } & No & 1 & & - & - \\
\hline & Yes & $1.45(1.15-1.83)$ & 0.002 & & \\
\hline BMI (increase of $1 \mathrm{~kg} / \mathrm{m}^{2}$ ) & & $0.97(0.95-1.00)$ & 0.028 & $0.97(0.95-1.00)$ & 0.028 \\
\hline \multirow[t]{2}{*}{ Current smoker } & No & 1 & & 1 & \\
\hline & Yes & $1.56(1.14-2.13)$ & 0.005 & $1.56(1.12-2.17)$ & 0.009 \\
\hline \multirow[t]{2}{*}{ Exercise in past 2 weeks } & No & 1 & & 1 & \\
\hline & Yes & $0.68(0.54-0.85)$ & 0.001 & $0.64(0.50-0.82)$ & $<0.001$ \\
\hline \multirow[t]{2}{*}{ Indigenous Australian } & No & 1 & & 1 & \\
\hline & Yes & $3.31(1.51-7.26)$ & 0.003 & $2.34(1.00-5.50)$ & 0.051 \\
\hline \multirow[t]{2}{*}{ CHD } & No & na & & 1 & \\
\hline & Yes & & & $1.69(1.34-2.14)$ & $<0.001$ \\
\hline \multirow[t]{2}{*}{ CVD } & No & na & & 1 & \\
\hline & Yes & & & $1.60(1.18-2.16)$ & 0.002 \\
\hline $\mathrm{Ln}(\mathrm{ACR})(\mathrm{mg} / \mathrm{mmol})$ & & na & & $1.18(1.09-1.27)$ & $<0.001$ \\
\hline \multirow[t]{2}{*}{ Retinopathy } & No & na & & 1 & \\
\hline & Yes & & & $1.80(1.37-2.35)$ & $<0.001$ \\
\hline \multirow[t]{2}{*}{ Neuropathy } & No & na & & 1 & \\
\hline & Yes & & & $1.78(1.37-2.22)$ & $<0.001$ \\
\hline \multirow[t]{2}{*}{ Depression } & No & 1 & & 1 & \\
\hline & Yes & $1.38(1.10-1.73)$ & 0.005 & $1.21(0.95-1.55)$ & 0.12 \\
\hline
\end{tabular}

$D M$ diabetes mellitus, $n a$ not applicable

Baseline demographic, diabetes-specific and cardiovascular risk factors were examined in Model A and diabetic complications were added in Model B 


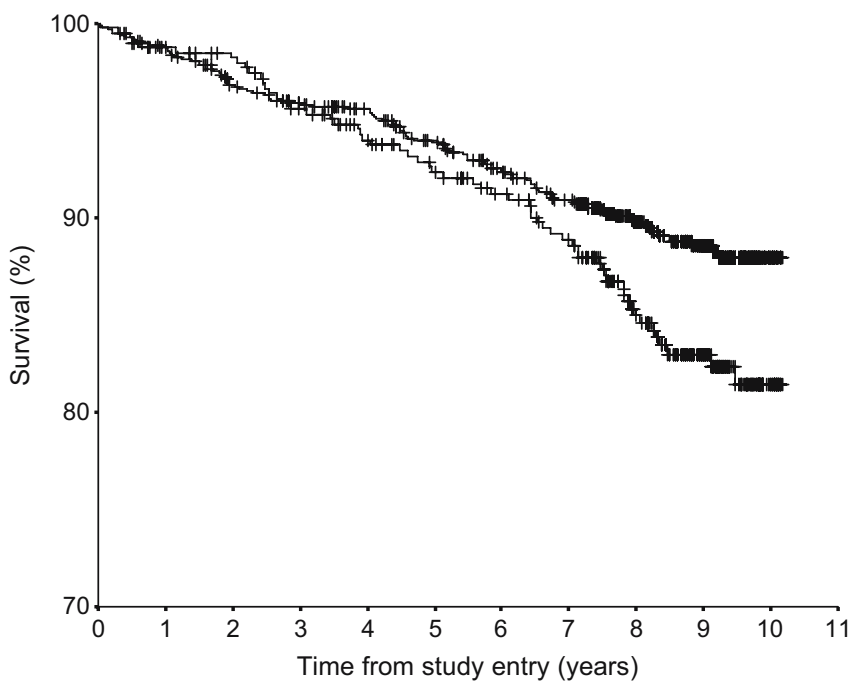

Fig. 2 Survival probability curves derived from Kaplan-Meier analysis of percentages of patients remaining alive (or deceased from non-cardiac causes) in two groups of patients defined by baseline depression status. The upper line denotes patients who were free of depression at baseline. The crosses indicate censored data points

only for age, sex, diabetes duration and indigenous ethnicity, depression status was independently associated with time to death with a significant excess cardiac mortality of $60.0 \%(95 \%$ CI $15.5-123.3 \%, p=0.005)$.

\section{Discussion}

We investigated the impact of co-morbid depression on mortality in a large cohort of Australian patients with type 2 diabetes who were followed for an average of 7.8 years. Other studies have found that depression is common in those with diabetes [1] and approaching one-third of our patients were depressed by our validated criteria. However, after adjusting for a range of other significant predictors, including diabetic microvascular complications and macrovascular disease, depression was not a significant determinant of either all-cause or cardiac mortality in our cohort.

Although baseline clinical depression was a significant predictor of mortality in univariate statistics, Cox modelling showed that other variables, particularly the presence of baseline micro- and macrovascular complications, had stronger relationships with mortality than depression. The depressed patients had a higher prevalence of CHD, CVD and nephropathy at baseline. This suggests either that depression arose secondary to diabetic complications (i.e. as a result of the burden of disease) or that depression was an aetiological factor in the development of micro- and macroangiopathy through behavioural effects [25] and/or direct pathophysiological changes [26, 27].

Our results indicate that behavioural effects secondary to depression may be at least partly responsible for the increased mortality rates. The depressed subjects took less physical exercise and were no more likely to be taking lipid-lowering therapy despite having a higher prevalence

Table 3 Cox proportional hazards models of baseline predictors of time to death from cardiac causes in patients with type 2 diabetes

\begin{tabular}{|c|c|c|c|c|c|}
\hline & & $\begin{array}{l}\text { Model A hazard ratio } \\
(95 \% \mathrm{CI})\end{array}$ & $p$ value & $\begin{array}{l}\text { Model B hazard ratio } \\
(95 \% \mathrm{CI})\end{array}$ & $p$ value \\
\hline Age (increase of 1 year) & & $1.11(1.08-1.13)$ & $<0.001$ & $1.10(1.08-1.13)$ & $<0.001$ \\
\hline \multirow[t]{2}{*}{ Sex } & Female & 1 & & 1 & \\
\hline & Male & $1.78(1.28-2.49)$ & 0.001 & $1.73(1.20-2.51)$ & 0.004 \\
\hline Diabetes duration (increase of 1 year) & & $1.02(1.00-1.04)$ & 0.030 & - & - \\
\hline $\mathrm{HbA}_{1} \mathrm{c}$ (increase of $1 \%$ ) & & $1.21(1.10-1.33)$ & $<0.001$ & $1.13(1.02-1.26)$ & 0.020 \\
\hline \multirow[t]{2}{*}{ BP-lowering therapy } & No & 1 & & - & - \\
\hline & yes & $2.39(1.63-3.50)$ & $<0.001$ & & \\
\hline \multirow[t]{2}{*}{ Current smoker } & No & 1 & & 1 & \\
\hline & Yes & $1.84(1.16-2.92)$ & 0.010 & $2.09(1.28-3.43)$ & 0.003 \\
\hline \multirow[t]{2}{*}{ Indigenous Australian } & No & 1 & & 1 & \\
\hline & Yes & $5.51(2.15-14.14)$ & $<0.001$ & $3.42(1.17-10.00)$ & 0.024 \\
\hline \multirow[t]{2}{*}{ CHD } & No & na & & 1 & \\
\hline & Yes & & & $3.08(2.12-4.49)$ & $<0.001$ \\
\hline \multirow[t]{2}{*}{ CVD } & No & na & & 1 & \\
\hline & Yes & & & $2.28(1.47-3.55)$ & $<0.001$ \\
\hline $\mathrm{Ln}(\mathrm{ACR})(\mathrm{mg} / \mathrm{mmol})$ & & na & & $1.17(1.04-1.32)$ & 0.008 \\
\hline \multirow[t]{2}{*}{ Retinopathy } & No & na & & 1 & \\
\hline & Yes & & & $1.86(1.23-2.82)$ & 0.003 \\
\hline \multirow[t]{2}{*}{ Neuropathy } & No & na & & 1 & \\
\hline & Yes & & & $1.95(1.35-2.82)$ & $<0.001$ \\
\hline \multirow[t]{2}{*}{ Depression } & No & 1 & & 1 & \\
\hline & Yes & $1.56(1.11-2.18)$ & 0.010 & $1.15(0.80-1.68)$ & 0.45 \\
\hline
\end{tabular}

na not applicable 
of dyslipidaemia. These findings parallel those in a study of diabetic subjects with major depression who had difficulty adhering to diet and exercise programmes and who had reduced compliance with prescribed medications [28]. Such behavioural attributes would be expected to contribute to the development and progression of both macroangiopathy and renal disease.

Given that there is evidence of an independent causal link between depression, CHD and cardiac death in the general population $[12,13]$, the present study suggests that this does not apply in patients with type 2 diabetes. Determining whether the relationship between depression and mortality is real with diabetic complications as the mechanism, or an artefact, i.e. that complications precede depression or both occur secondary to some other cause, would require more information on the sequence of events. The literature on this topic is confusing with studies demonstrating that depression can predate the onset of diabetes $[4,5]$ and that depression is associated with the development of diabetic complications [9].

In the only longitudinal study to consider the causes of poor outcomes as a result of depression in diabetes, one conducted in older Mexican Americans [9], there was a significant relationship between baseline depression and the subsequent development of micro- and macrovascular complications and all-cause mortality. However, the presence of complications was not adjusted for in the models examining mortality, while other data, including biochemical variables such as $\mathrm{HbA}_{1} \mathrm{c}$ and serum lipids, smoking and alcohol history, exercise history and treatment for vascular risk factors, were not available for analysis [9]. A recent examination of the First National Health and Nutrition Examination Survey in the USA found an excess all-cause mortality rate in diabetic subjects with depressive symptoms, but did not examine cardiac mortality or the impact of complications [29].

The characteristics of our depressed patients were consistent with reports from other studies where depression was more common in females [30,31] and was associated with physical inactivity [4] and diabetic complications [7]. We also found that depressed patients had worse lipid profiles. In contrast to a recent meta-analysis [8], we found no difference in glycaemic control or in blood glucoselowering treatment between patients with or without depression. This inconsistency may reflect patient selection since the studies included in the meta-analysis had small sample sizes [8]. Few of our depressed patients were treated with anti-depressant medication, consistent with the suggestion that depression in diabetic subjects is often undiagnosed and under-treated [32].

The major limitation of the present study is that we did not utilise a validated depression instrument but adapted a subscale embedded in a quality-of-life measure. Previous authors have used similar methodology [33] and we validated our method in an independent sample. We used the term clinical depression to denote major depression, minor depression or dysthymia, but could not distinguish between the categories even though major depression is more strongly associated with poorer outcomes [7]. Inventories of depressive symptoms may be overly sensitive to somatic complaints in chronic medical conditions such as appetite change or fatigue associated with hyperglycaemia, although diabetes may not be a major confounder of the diagnosis of depression [34]. For these reasons, we are likely to have overestimated the prevalence of depression, thereby diluting potential differences between depressed and non-depressed subjects. Our estimated prevalence rate of depression was consistent with rates for depressive symptomatology that have been reported in a meta-analysis of studies of diabetic populations and was higher than rates based on diagnostic interviews [1]. Depression and complications were assessed only at baseline and we have no data on the duration, recurrence or impact of depression treatment. It might be expected that prolonged depression, as has been documented in patients with diabetes [25], would be required for significant effects on mortality. We also have not explored the impact of incident or progression of complications on important self-care behaviours.

The strengths of the present study are the accuracy of diabetes diagnosis, the representative nature of the cohort and the detailed assessment of a large number of important diabetes-related variables and co-morbidities. This includes supplementation of the self-reports with clinical examinations and laboratory and hospital data. In addition, the Western Australian Data Linkage System provided a unique resource to accurately determine the cause and date of death [22].

Although we did not find depression to be an independent determinant of death, our data suggest that it may be a major contributing factor to other important prognostic variables. Further research is required to confirm our findings and to consider whether and how depression has an impact on the development and progression of diabetic complications. Recent trials indicate that effective treatment of depression is possible in diabetic patients and can lead to improvements in the mood disorder [35, 36]. Future studies of the treatment of depression in patients with diabetes should include a consideration of how to optimise the management of diabetic complications to improve the prognosis of type 2 diabetes.

Acknowledgement The Fremantle Diabetes Study was funded by the Raine Foundation, University of Western Australia.

\section{References}

1. Anderson RJ, Freedland KE, Clouse RE, Lustman PJ (2001) The prevalence of comorbid depression in adults with diabetes: a meta-analysis. Diabetes Care 24:1069-1075

2. Amato L, Paolisso G, Cacciatore F et al (1996) Non-insulindependent diabetes mellitus is associated with a greater prevalence of depression in the elderly. Diabetes Metab 22:314-318

3. Black SA, Goodwin JS, Markides KS (1998) The association between chronic diseases and depressive symptomatology in older Mexican Americans. J Gerontol Med Sci 53A: M188-M194 
4. Eaton WE, Armenian H, Gallo J, Pratt L, Ford DE (1996) Depression and risk of onset of type II diabetes: a prospective population-based study. Diabetes Care 20:1097-1102

5. Kawakami N, Takasuka N, Shimizu H, Ishibashi H (1999) Depressive symptoms and the occurrence of type 2 diabetes among Japanese men. Diabetes Care 22:1071-1076

6. Peyrot M (2003) Depression: a quiet killer by any name. Diabetes Care 26:2952-2953

7. De Groot M, Anderson R, Freedland KL, Clouse RE, Lustman PJ (2001) Association of depression and diabetes complications: a meta-analysis. Psychosom Med 63:619-630

8. Lustman PJ, Anderson RJ, Freedland KE, De Groot M, Carney RM, Clouse RE (2000) Depression and poor glycemic control. Diabetes Care 23:934-942

9. Black SA, Markides KS, Ray LA (2003) Depression predicts increased incidence of adverse health outcomes in older Mexican Americans with type 2 diabetes. Diabetes Care 26:2822-2828

10. Hurst RT, Lee RW (2003) Increased incidence of coronary atherosclerosis in type 2 diabetes mellitus: mechanisms and management. Ann Intern Med 139:824-834

11. Moss SE, Klein R, Klein DE (1991) Cause-specific mortality in a population-based study of diabetes. Am J Public Health 81:1158-1162

12. Wulsin LR, Singal BM (2003) Do depressive symptoms increase the risk for the onset of coronary disease? A systematic quantitative review. Psychosom Med 65:201-210

13. Hemingway H, Marmot M (1999) Psychosocial factors in the aetiology and prognosis of coronary heart disease: systematic review of prospective cohort studies. BMJ 318:1460-1467

14. Davis TM, Zimmet P, Davis WA, Bruce DG, Fida S, Mackay IR (2000) Autoantibodies to glutamic acid decarboxylase in diabetic patients from a multi-ethnic Australian community: the Fremantle Diabetes Study. Diabetic Med 17:667-674

15. Bruce DG, Davis WA, Davis TME (2000) Glycemic control in older diabetic patients in the Fremantle Diabetes Study. J Am Geriatr Soc 48:1449-1453

16. Davis TME, Davis W, Mulder JW, Fortune P, Bruce DG (2004) Silent myocardial infarction and its prognosis in a communitybased cohort of diabetic patients: the Fremantle Diabetes Study. Diabetologia 47:395-399

17. Bruce DG, Davis WA, Cull CA, Davis TME (2003) Diabetes education and knowledge in patients with type 2 diabetes from the community: the Fremantle Diabetes Study. J Diabetes Its Complicat 17:82-89

18. Feldman EL, Stevens MJ, Thomas PK, Brown MB, Canal N, Greene DA (1994) A practical two-step quantitative clinical and electrophysiological assessment for the diagnosis and staging of diabetic neuropathy. Diabetes Care 17:1281-1289

19. Gudex C, Kind P (1989) The QALY toolkit. Centre for Health Economics, University of York, York
20. Lebowitz BD, Pearson JL, Schneider LS et al (1997) Diagnosis and treatment of depression in late life. Consensus statement update. JAMA 278:1186-1190

21. Lavretsky H, Kumar A (2002) Clinically significant non-major depression. Old concepts, new insights. Am J Geriatr Psychiatr 10:239-255

22. Holman CDJ, Bass AJ, Rouse IL, Hobbs MST (1999) Population-based linkage of health records in Western Australia: development of a health services research linked database. Aust N Z J Public Health 23: 453-459

23. UKPDS Group (1998) Risk factors for coronary artery disease in non-insulin dependent diabetes (UKPDS 23). BMJ 316:823828

24. Therneau TM, Grambsch PM (2000) Testing proportional hazards. In: Therneau TM, Grambsch PM (eds). Modeling survival data: extending the Cox model. Springer, Berlin Heidelberg New York, pp 127-152

25. Peyrot M, Rubin R (1999) Persistence of depressive symptoms in diabetic adults. Diabetes Care 22:448-452

26. Checkley S (1996) The neuroendocrinology of depression and chronic stress. Br Med Bull 52:597-617

27. Herbert TB, Cohen S (1993) Depression and immunity: a metaanalytic review. Psychol Bull 113:472-486

28. Lin EH, Katon W, Von Korff M et al (2004) Relationship of depression and diabetes self-care, medication adherence and preventive care. Diabetes Care 27: 2154-2160

29. Zhang X, Norris SL, Gregg EW, Cheng YJ, Beckles G, Kahn HS (2005) Depressive symptoms and mortality among persons with and without diabetes. Am J Epidemiol 161:652-660

30. Katon W, Von Korff M, Ciechanowski P et al (2004) Behavioral and clinical factors with depression among individuals with diabetes. Diabetes Care 27:914-920

31. Egede L, Zheng D (2003) Independent factors associated with major depressive disorder in a national sample of individuals with diabetes. Diabetes Care 26:104-111

32. Lustman PJ, Harper GW (1987) Nonpsychiatric physicians' identification and treatment of depression in patients with diabetes. Compr Psychiatry 28:22-27

33. Testa MA, Simonson DC (1998) Health economic benefits and quality of life during improved glycemic control in patients with type 2 diabetes mellitus. JAMA 280:1490-1496

34. Lustman PJ, Clouse RE, Griffith LS, Carney RM, Freedland KE (1997) Screening for depression using the Beck Depression Inventory. Psychosom Med 59:24-31

35. Williams JW Jr, Katon W, Lin EH et al (2004) Effectiveness of depression care management for older adults with coexisting depression and diabetes mellitus. Ann Int Med 140:1015-1024

36. Katon WJ, Von Korff M, Lin EHB et al (2004) The Pathways Study: a randomised trial of collaborative care in patients with diabetes and depression. Arch Gen Psychiatry 61:1042-1049 